\title{
Influence of Age and School Type on Reform Practices Performed by School Heads
}

\author{
Innocent Kwame Bedi \\ Hasso Kukemelk \\ Institute of Education, \\ The University of Tartu, \\ Salme 1a, 50103, Tartu, Estonia
}

DOI: https://doi.org/10.36941/mjss-2021-0o46

\begin{abstract}
The purpose of this study is to examine the level of implementing reform practices and their resulting stress and to explore the influence of age, gender, school type and tracking type on performing reform practices and the perceived stress in implementing reforms among school leaders. A quantitative research design was used with respondents sampled from among senior high school heads. The data were analysed using multinomial logistic regression to examine the influence of demographic (age and gender) and school variables (school type and tracking type) on implementing reform and its perceived stressfulness. The findings showed that on implementing reforms and its inherent stressfulness, a majority of school heads 'always' perform reform duties and a greater proportion reported high-stress levels in implementing reforms from 'somewhat causes' stress to 'causes great' stress. Regarding demographic and school variables, age was a significant negative predictor of implementing reforms, indicating that younger heads were more likely to perform reform functions than older heads while school type significantly influences stress level in implementing reforms, implying that heads in boarding schools were more likely to experience higher stress levels in implementing reforms than heads in day schools. The authors recommended continuous in-service training for school heads, the practice of distributive leadership style and provision of infrastructure to phase out the doubletrack (shift system) in some schools.
\end{abstract}

Keywords: reform, practices, job stress, age, school type

\section{Introduction}

The task of implementing educational reforms at the school level falls on school heads as leaders, stakeholders (Kukemelk \& Ginter, 2016; Huber, 2010) and human participants in the educational change process (Fullan \& Stiegelbauer, 1991). The positions of the school heads are of utmost significance because sustainable reforms in schools depend largely on the strategic leadership of heads (Fullan, 1982). Unfortunately, the unanswered question is: Do school heads implement reform policies at the school level? Educational reforms in Ghana date back historically (Zame et al., 2008) from the arrival of colonial masters to the present day. One notable reform in the colonial era was the 16 principles formulated by Governor Guggisberg (1919-1927), who advocated equitable 
comprehensive elementary education for both boys and girls (Ministry of Education, 2001). This was followed by the 1951 Accelerated Development plan (Kadingdi, 2004), the 1987 education reform, the 2007 reform in the Fourth Republic (Adu-Gyamfi et al., 2016) and now the Free Senior High school policy (FSHS, 2017) being implemented across the country.

From a broader view, the Ministry of Education published the Education Strategic Plan 20182030 and outlined 12 reforms to address weaknesses in the education sector. The goals of the reforms were to transform the education sector to make it more relevant in meeting the human resource and development needs of the country. It is expected to contribute to the goals of the Education Sector Plan (ESP) and the United Nations Sustainable Development Goal 4 (SDG 4) to improve learning outcomes, especially at the pre-tertiary level. The priorities of the reforms are in sum to improve learning outcomes, thereby enhancing accountability and equity at all levels of education.

Education administration in Ghana is top-down. Consequently, reform policies are centralised, planned and led by policymakers or administrators (Tikkanen, Pyhältö, Pietarinen \& Soini, 2019). Though this strategy has benefits (Pietarinen et al., 2017; Petko et al., 2015), it was reported to have a weak impact on the day-to-day functioning of reform implementers as school heads do not seem to own the reforms (Chow, 2013; Ng, 2009 cited in Tikkanen, et al., 2019). This study, therefore, sought to determine whether school heads implement reforms and how stressed they feel when implementing reforms at the school level. Also, to determine whether school type, age, gender and system of school influence the implementation of reforms.

\section{Job Stress Situation among School Heads}

School heads as managers of education delivery are expected to implement reforms introduced in education at the school level (Denecker, 2019). However, the implementation of these reforms, like any other function performed by heads, is stressful (Stynes, Mcnamara \& O'Hara, (2018).

Prior studies on job stress among school heads reported moderate to high levels of stress (Riley, 2018) in discharging their functions, which Rich (2010) warned were overwhelming. The incidence of job stress in teaching and among heads is not limited to one country. All over the world, school systems are reported to be experiencing difficulties due to the increasing tasks of school heads, which harm their health and scaring away recruits for the position (Whitaker, 2003; Chapman, 2005). Riley (2018), in investigating school heads' health and well-being in Australia, revealed that heads experience significantly higher stress levels compared to the general population. Similar results were reported in studies conducted among school principals in Indiana (Boyland, 2011) and Ireland (Darmody \& Smyth, 2016), where high-stress levels were reported.

Research also touched on sources of stress among heads. Age, type of school and the federal state (region of school) were reported to have influenced the stress level of heads (Dadaczynski \& Paulus, 2016). In examining well-being, job stress with age, type of school and federal state, Dadaczynski and Paulus (2016) reported a significant difference for well-being for age, type of school and federal state and concluded that younger principals form an important target group for health promotion and prevention measures as high job-related stress was reported among them.

Despite knowledge on job stress among school heads, research on specific practices that influence job stress and the contributions of demographic and school variables have been sparse. This study, therefore, contributes to the literature by examining the task of implementing reforms by school heads, its stressfulness and the influence of age, sex type of school (day or boarding) and tracking type (double track or single track) on implementing reforms and the resulting stress.

\section{Method}

The study was part of a quantitative design survey investigating the profile of activities performed by school heads and the resulting stress. In the sample, 195 school heads from senior high schools (SHSs) consented to and participated in the study. The sample characteristics were: gender (males = 
$79 \%$, female $=21 \%$ ); age (average $=49.6$ years, modal age $=49$ years); and work experience as heads $(1-5$ years $=77.9 \% ; 6-10$ years $=16.4 \% ; 11-15$ years $=4.6 \%)$. The school variables are type of school (boarding $=74.4 \%$, day $=26.6 \%)$, tracking $($ shift $)$ system $(64.6 \%=$ track system $[$ shift], $35.4 \%=$ single track [no shift system]).

The item investigating the problem of interest as part of the adapted instrument measuring school heads' practices (Kukemelk \& Mikk, 2015; Huber, Wolfgramm \& Kilic, 2013) and among the nine items under the subscale quality development. The scale was measured on a five-point Likert scale as $1=$ never performed to $5=$ always performed on the performed scale and $1=$ causes no stress to $5=$ causes great stress on the practices' perceived stressful scale with high scores meaning a high presence of the attribute being measured. The two scales were recoded into three ordinal levels as 'not performed', 'sometimes performed' and 'always performed' on the practices' perform scale and 'causes no stress', 'causes somewhat stress' and 'causes great stress' on the practices' perceived stressful scale. The subscale reported high-reliability values of 0.83 and 0.91 , respectively, as against the ideal value of .7 (Griethuijsen et al., 2014).

Data analysis consisted of ordinal logistic regression (OLR), which enabled the prediction and weighing of the relationship between response variables: levels of practices performed and level of practices perceived as stressful and the explanatory variables: tracking type, gender, age and school type. The five-point scale response variables were recoded into three response levels: never performed $=0$, sometimes performed $=1$ and always performed $=2$ on the practices performed scale and causes no stress $=0$, causes somewhat stress $=1$ and causes great stress $=2$ on the practices' perceived stressful scale. High scores on the performed and stressful scales indicate high performance and high-stress levels. The explanatory variables, gender $($ males $=0$, female $=1$ ), tracking type (double track $=0$, single track $=1$ ) and school type $($ day $=0$, boarding $=1)$, were coded into dichotomous variables with age as a continuous variable. Descriptive statistics were also used to compute the counts of variables.

\section{Results}

\subsection{Descriptive Statistics}

The count distributions of performing activities related to implementing reforms and the perceived stressful nature of performing such practices were analysed. The result showed a majority (74.4\%) of school heads 'always' perform reform practices while $21.0 \%$ 'sometimes' perform with less than $5 \%$ not performing such practices. Regarding how stressful implementing reforms were, the results showed a little above half (51.3\%) of heads reported 'somewhat' stressful, while $40 \%$ indicated 'causes great stress' and less than $10 \%$ revealed implementing reforms 'causes no stress' at all. The mean, standard deviation and mode were also computed. Performing reform implementation (mean = 2.70; $\mathrm{SD}=.55 ;$ mode $=3.00$ ) and stress level in implementing reforms (mean $=2.31 ; \mathrm{SD}=.63$; mode $=2.00$ ). The results showed that most heads always perform reform-related duties (mode $=3$ ), and a majority feel somewhat stressed in performing reform-related duties $($ mode $=2)$. See Table 1 .

Table 1: Descriptive statistics of performing and stress levels of reform implementation

\begin{tabular}{llll}
\hline & Mean & Std. Dev. & Mode \\
\hline Implementing reforms & 2.70 & .55 & 3.00 \\
Stress in implementing reforms & 2.31 & .63 & 2.00 \\
\hline
\end{tabular}

4.2 Relationship among demographic, school systems' variables and performing reform implementation practices

Demographic variables like gender and age with school variables such as school type and tracking 
type influence on implementing reform-related practices were assessed and presented in Table 2. Assessment of the model showed good fit to the data, with deviance $\left(\mathrm{X}^{2}[174]=174.56, \mathrm{P}>0.05\right)$ and Pearson's chi-squared test $\left(\mathrm{X}^{2}[174]=139.17, \mathrm{P}>0.05\right)$ revealing a non-significant result indicating good model fit. This implied the data fit the model well (Field, 2018; Petrucci, 2009). The result revealed age was a negative significant predictor of performing duties related to implementing reform in schools $(\mathrm{B}=-.06$, Wald $=5.26, \mathrm{P}<.05)$. This means there was a predicted decrease of .06 in the $\log$ odds of heads scoring higher on performing reform implementation practices. Scoring higher was more likely to decrease with an increase in age - younger heads were more likely to perform reform implementation practices than older heads. Gender, tracking type and school type were nonsignificant predictors of performing reform implementation practices, but the results were worth discussing. Though gender was not significant in the model $(\mathrm{B}=-.71$, Wald $=3.37, \mathrm{P}>.05)$, the $\log$ odds of being in the higher-performing (implementation) category was .71 points lower for heads identified as females than for heads identified as males. In other words, male heads were more likely to perform reform implementation duties than female heads. Type of tracking was also not significant $(\mathrm{B}=-.14$, Wald $=.16, \mathrm{P}>.05)$. The types of tracking were double track (shift system) and single track (no shift system). The non-significant result indicated that the log odds of being in the higher category on performing reform implementation duties were .14 points lower for single-track school heads than for double-track school heads. In other words, heads in double-track schools were more likely to perform functions related to implementing reforms than heads in single-track schools. The next non-significant predictor was school type $(\mathrm{B}=-.19$, Wald $=.13, \mathrm{P}>.05)$. School type refers to whether the school is a strictly day or boarding and day school. Though working in a particular school type did not statistically predict a higher level of implementation of reforms, the results showed that the log-odds were .19 lower for heads in boarding and day schools than for heads in strictly day schools. This further implied that there was a decreasing probability for boarding and day school heads for implementing reforms than for heads in strictly day schools. In sum, the results satisfied the test of parallel lines' assumption with non-significant proportional odds $\left(\mathrm{X}^{2}[4]=2.65, \mathrm{P}\right.$ $>0.05$ ), meaning the relationship between the explanatory variables was the same across all possible comparisons (Osborne 2017) involving the response variable. See Appendix 1.

Table 2: Parameter Estimates - Performing implementing reform practices against demographic and school variables

\begin{tabular}{|c|c|c|c|c|c|c|}
\hline & & Estimate & Std. Error & Wald & $\mathrm{df}$ & Sig. \\
\hline \multirow[t]{2}{*}{ Threshold } & (Performing_Reform implementation_level = 1.0o) & -6.42 & 1.44 & 20.04 & 1 & .000 \\
\hline & (Performing_Reform_implementation_level = 2.00) & $-4 \cdot 40$ & 1.38 & 10.17 & 1 & .001 \\
\hline \multirow[t]{4}{*}{ Location } & Tracking Type & -.14 & .36 & .16 & 1 & .691 \\
\hline & Gender & -.71 & .39 & $3 \cdot 37$ & 1 & .067 \\
\hline & Age & -.06 & .03 & 5.26 & 1 & .002 \\
\hline & Sch_type & -.19 & .54 & .13 & 1 & .724 \\
\hline
\end{tabular}

${ }^{*} \mathrm{DV}$ - Level of performing reform-related practices

\subsection{Relationship among demographic, school systems' variables and stress level of implementing reforms}

The perceived stressful nature of reform implementation (response variable) was recoded into three levels: causes no stress, somewhat causes stress, and causes great stress. Higher scores on the scale indicate a higher level of stress in performing reform implementation duties by school heads. OLR analysis revealed that the model was a good fit to the data. The deviance $\left(\mathrm{X}^{2}[174]=179.08, \mathrm{P}>0.05\right)$ and Pearson's Chi-squared test $\left(\mathrm{X}^{2}[174]=186.30, \mathrm{P}>0.05\right)$ showed the model fits the data well (ibid.). The respective examination of explanatory variables - gender, tracking type, school type and age revealed that school type was a significant predictor of perceived stress in performing reform 
implementation in the model $(\mathrm{B}=1.06$, Wald $=5.48, \mathrm{P}<.05)$, implying that the log odds of being in a higher stress category was 1.06 points higher for heads in boarding and day schools than for heads in strictly day schools. The results for the gender of heads were not significant $(\mathrm{B}=-.52$, Wald $=2.12, \mathrm{P}>$ .05) but mean that the log odds of scoring higher on the stress of performing reform implementation was 0.52 points lower for persons identified as female as male (males experience less stress in performing reform implementation duties than females). Regarding tracking type, the result was not a significant predictor of the stressful nature of implementing reforms $(\mathrm{B}=-.06$, Wald $=.04, \mathrm{P}>.05)$. However, on average, the log odds of being in a higher stress category were .06 lower for heads in single-track schools than for heads in double-track schools. Lastly, age was not a significant predictor of the stressful nature of performing reform implementation $(\mathrm{B}=-.02$, Wald $=.87, \mathrm{P}>.05)$, implying that for every year increase in age, there was a predicted decrease of .02 points in the log odds of higher stress levels in performing reform implementation practices for older heads. This implied that younger heads were more likely to experience stress in implementing reforms than older heads. On the whole, the proportional odds' assumption was satisfied as the test of parallel lines was not significant $\left(\mathrm{X}^{2}[4]=3.30, \mathrm{P}>0.05\right)$. See Table 3 .

Table 3: Parameter estimates - perceived stress level in implementing reforms against demographic and school variables

\begin{tabular}{|c|c|c|c|c|c|c|}
\hline & & Estimate & Std. Error & Wald & df & Sig. \\
\hline \multirow[t]{2}{*}{ Threshold } & (Stress in implementing Reform_level $=1.00$ ) & -2.62 & 1.17 & 4.99 & 1 & .03 \\
\hline & (Stress in implementing_Reform_level = 2.0o) & .25 & 1.16 & .05 & 1 & .83 \\
\hline \multirow[t]{4}{*}{ Location } & Tracking Type & -.06 & .30 & .04 & 1 & .85 \\
\hline & Gender & -.52 & .35 & 2.12 & 1 & .15 \\
\hline & Age & -.02 & .02 & .87 & 1 & .35 \\
\hline & Sch_type & 1.06 & .45 & $5 \cdot 45$ & 1 & .02 \\
\hline
\end{tabular}

${ }^{*} \mathrm{DV}$ - Level of perceived stress in performing reform-related practices

\section{Discussion}

Studies have recognised the value of school heads in school administration and described their duties as complex and highly stressful with demanding practices (De Jong \& Yankey, 2017). Though researchers have revealed some duties of school heads as stressful (Boyland, 2011; Juma \& Simatwa, 2016; Huber et al., 2017; Denecker, 2019), studies specifically assessing the performance of reformrelated duties and the inherent stress and impact of demographic and school variables are rare.

The aim of this study was thus to examine the implementation of reform duties among school heads, the perceived stressfulness of implementing reforms and the influence of age, gender, school type and tracking type on performing reform duties and perceived stressfulness. The findings are discussed next.

School heads as stakeholders in the education delivery chain (Kukemelk \& Ginter, 2016) perform duties to shape educational policies and school improvement in many countries (Huber, 2010). Consequently, their work effectiveness and efficiency together with their health, resilience and wellbeing have become a major concern for policymakers and educational authorities and school leader associations (Huber, 2010). Therefore, evidence that a majority of heads 'always' performed reformrelated practices was consistent with the findings of Esia-Donkoh (2014), who concluded that school heads generally perform functions directed at improving the management of the school effectively through with challenges. The second leg of the evidence showed that a majority of heads perceived implementing reform functions as 'somewhat' causes stress and 'causes great stress'. This did not deviate from prior findings that school heads reported moderate to high levels of stress in the discharge of their duties (Darmody \& Smyth, 2016; Juma \& Simatwa, 2016; Denecker, 2019). Furthermore, it was consistent with the findings of Bedi and Kukemelk (2019; 2020) that school heads continue to perform practices though it was perceived as stressful to do so. One plausible reason for 
this result was the fact that reforms do not originate from the school level. In most instances, these were imposed on heads (Denecker, 2019) and, given that administration of schools is top-down, the heads had no choice but to implement the reform as directed by the higher authority.

It was also evident that in predicting the level of performing reform-related practices, age, gender, school type and tracking type had varying impacts. While age as a variable had a significant negative impact, younger heads were predicted to perform reform practices more than older heads. Male heads were also more likely to perform such practices than female heads. About the impact of school type and tracking type, the evidence was that in double-track schools, heads were more likely to perform reform duties than heads in single-track schools while heads in day schools were predicted to perform reform duties more than heads in boarding schools.

In contrast, younger heads perceived implementing reforms as more stressful than older heads, and male heads were predicted to perceive implementing reforms as more stressful than female heads. The results that younger heads experience more stress than older heads seem to be in line with the results of Dadaczynski and Paulus (2016) that attention needs to be paid to the prevention of high job stress among younger heads. According to Borg and Riding (1991), school variables like type and size of the school influenced stress level; therefore, the results that heads in double-track schools perceived implementing reforms as more stressful than heads in single-track schools while heads in boarding schools were more stressed in implementing reform duties than day school heads are additions to the knowledge about job stressors in the education sector.

\section{Conclusion}

From the findings established above, the researchers offer the following recommendations to guide the policy and management of schools. As age was inversely related to preforming reform duties, inservice training should be routine to keep all heads abreast of current trends in educational administration and management. Also, school heads in boarding schools should adopt a distributive leadership style to share the responsibilities among staff and thus reduce their workload and stress (Harris, 2003). The result provided education managers at the policy level with information about the dynamics of implementing reforms at the school level, which could be used to develop and formulate strategies to guide the recruitment of heads and to lessen the burden of work on heads. Given that type of school, the system of the school, age and gender had some level of influence on performance and stress, it is important that conditions be improved and heads involved in drafting reforms to ensure 'ownership' of reforms (Chow, 2013; Ng, 2009, cited in Tikkanen et al., 2019) to enhance increased productivity and effectiveness.

Though findings may be limited to secondary education in Ghana, which is centrally controlled with limited powers by the heads, these are also applicable to countries with a similar educational management system and culture. The study was not limited, however, to a particular reform being implemented at the school level.

In sum, the knowledge of variables that influence the performance of practices related to reform and stress among school heads is essential when seeking to improve the quality and effectiveness of a school. As school heads provide leadership and ensure school effectiveness and efficiency (Cheng, 1994, cited in Wang et al., 2018), the findings of this study should provide background information to guide developments in the education sector.

\section{Acknowledgement}

This project was supported by the European Regional Development Fund through the Archimedes Foundation. 


\section{References}

Adu-Gyamfir, S., Donko, W.J. \& Addo, A.A. (2016). Educational Reforms in Ghana: Past and Present. Journal of Education and Human Development, Vol. 5, No. 3, pp. 158-172. DOI: 10.15640/jehd.v5n3a17

Anastasiou, S. \& Papakonstantinou, G. (2014). Factors affecting job satisfaction, stress and work performance of secondary education teachers in Epirus, NW Greece. International Journal of Management in Education, Volume 8, Issue 1, 2014, pages 37-53

Bedi, I.K. \& Kukemelk, H. (2019). School Principals' functions and its resulting job stress in the context of Ghana. Presentation at the World Education Leadership Symposium (WELS) 2019, hosted by the IBB of the PH Zug on September 25th-27th 2019 in Zug. Available at: WELS.EduLead.net

Bedi, I.K., \& Kukemelk, H. (2020). School Heads' Practices Defined. Journal of Educational and Social Research, 10(5), 187-199. DOI: https://doi.org/10.36941/jesr-2020-0098

Borg, M.G. \& Riding, R.J. (1991). Towards a model for the determinants of occupational stress among schoolteachers. European Journal of Psychology of Education, Volume 6, Issue 4, December 1991, pages 355373

Boyland, L. (2011). Job stress and coping strategies of elementary principals: A statewide study. Current Issues in Education, 14(3). Retrieved from http://cie.asu.edu/ojs/index.php/cieatasu/article/view/8o6

Cooper, C.L. \& Kelly, M. (2018). Occupational stress in headteachers: A national UK study. Managerial, Occupational and Organizational Stress Research, 17 January 2018, pages 277-290.

Dadaczynski, K. \& Paulus, P. (2016). Wellbeing of school heads in Germany: Characteristics and associations with work and health. Pravention und Gesundheitsforderung, Volume 11, Issue 3, 1 August 2016, pages 171-176.

Darmody, M. \& Smyth, E. (2016). Primary school principals' job satisfaction and occupational stress. International Journal of Educational Management, Vol. 30 Issue: 1, pages. 115-128, https:// doi.org/10.1108/IJEM-12-20140162

De Jong, D., Grundmeyer, T. \& Yankey, J. (2017). Identifying and addressing themes of job dissatisfaction for secondary principals. School Leadership and Management, Volume 37, Issue 4, 8 August 2017, pages 354-371.

Denecker, C. (2019). School Principals' Work Stress in an Era of New Education Governance. Swiss Journal of Sociology 45(3), pages 447-466. Sciendo. DOI: 10.2478/sjs-2019-0021

Esia-Donkoh, K. (2014). Attaining School and Educational Goals: Duties of Head Teachers of Public Basic Schools in Ghana. Journal of Education and Practice, Vol. 5, No. 1, 2014.

Field, A. (2018). Discovering Statistics using IBM SPSS Statistics (5th Ed). Los Angeles: Sage.

Fullan, M. (1982). The Meaning of Educational Change. New York: Teachers College Press.

Fullan, M. \& Stiegelbauer, S. (1991). The New Meaning of Educational Change, 2nd ed. New York: Teachers College Press.

Gebrekirstos, H.A. (2015). Occupational Stress among Secondary School Teachers and Their Coping Strategies: The Case of Central Zone of Tigray Region. International Journal of Academic Research in Education and Review. Vol. 3(6), pages 143-157.

Harris, A. (2003). Distributed Leadership and School Improvement: Leading or Misleading? Educational Management Administration \& Leadership, Vol 32(1), pages 11-24; 039297. DOI: 10.1177/1741143204039297

Huber, S.G. (2010). School headship - International Perspectives, Studies in Educational Leadership 10, DOI 10.1007/978-90-481-3501-1_12, Springer Science Business Media B.V. 2010.

Huber, S., Tulowitzki, P. \& Hameyer, U. (2017). School Leadership and Curriculum: German Perspectives. Leadership and Policy in Schools, 16(2), pages 272-302.

Juma, J.K.A. \& Simatwa, E.M.W. (2016). Stress Management Coping Strategies Used by Female Principals in Kenya: A Case Study of Rachuonyo North and Homa Bay Sub Counties. Greener Journal of Educational Research, Vol. 6 (3), pp. 115-132, May 2016. DOI: http://doi.org/10.1558o/GJER.2016.3.051616o88

Kadingdi, S. (2004). "Policy Initiative for Change and Innovation in Basic Education Programmes in Ghana," Critical Review, Vol.4. No.2, 2004.

Kukemelk, H. \& Ginter, J. (2016). Estonia: School Leadership in Estonia. 2001-2013: A Decade of Research on School Principals, Studies in Educational Leadership. In H. Ärlestig et al. (eds.), Springer International Publishing Switzerland.

Ministry of Education Ghana (2018). Education Sector Analysis. Retrieved from https://www.globalpartnership.org/content/ghana-education-sector-analysis-2018

Ministry of Education Ghana (2018). Education strategic plan 2018-2030. Ghana. Retrieved from https://www.globalpartnership.org/content/education-strategic-plan-2018-2030-ghana

Osborne, J.W. (2017). Regression and Linear Modeling: Best Practices and Modern Methods. Thousand Oaks, CA: Sage. 
Petko, D., Egger, N., Cantieni, A. \& Wespi, B. (2015). Digital media adoption in schools: Bottom-up, top-down, complimentary or optional? Computers \& Education, 84, 49-61. https://doi. org/10.1016/j.compe du.2014.12.019

Petrucci, C.J. (2009). A primer for social worker researchers on how to conduct a multinomial logistic regression. Journal of Social Service Research, 35, 193-205.

Pietarinen, J., Pyhältö, K. \& Soini, T. (2017). Large-scale curriculum reform in Finland - exploring the interrelation between implementation strategy, the function of the reform, and curriculum coherence. The Curriculum Journal, 28(1), 22-40. https ://doi.org/10.1080/09585 176.2016.11792 05

Riley, P. (2018). The Australian Principal Occupational Health, Safety and Wellbeing Survey. 2017 Data. Fitzroy, Victoria, Australia: Australian Catholic University.

Stynes, M., Mcnamara, G., \& O’Hara , J. (2018). An analysis of day to day activities of a sample of primary school heads in Ireland. Egitim Arastirmalari - Eurasian Journal of Educational Research. Open Access Volume 2018, Issue 76, 2018, pages 93-112.

Tikkanen, L., Pyhältö, K., Pietarinen. J. \& Soini, T. (2019). Lessons learnt from a large scale curriculum reform: The strategies to enhance development work and reduce reform-related stress. Journal of Educational Change. https://doi.org/10.1007/s10833-019-09363-1

Zame, M. Y., Warren, C. H. \& Respress, T. (2008). 'Educational reform in Ghana: the leadership challenge', International Journal of Educational Management, Vol. 22 Issue: 2, pages 115-128, https://doi.org/10.1108/o9513540810853521

Appendix 1: Performed - Test of Parallel Lines

\begin{tabular}{lllll}
\hline Model & -2 Log Likelihood & Chi-Square & df & Sig. \\
\hline Null Hypothesis & 183.585 & & & \\
General & 180.932 & 2.652 & 4 & .618 \\
\hline
\end{tabular}

The null hypothesis states that the location parameters (slope coefficients) are the same across response categories ${ }^{a}$

a. Link function: Logit. 